Journal of

Accident and Emergency Medicine 1994

11, $144-148$

\title{
Management of minor head injuries in the accident and emergency department: the effect of an observation ward
}

\author{
S.R.BROWN, ${ }^{1}$ C. RAINE, ${ }^{2}$ C.E. ROBERTSON ${ }^{1}$ \& I.J.SWANN ${ }^{2}$ \\ ${ }^{1}$ Directorate of Accident and Emergency Medicine, Royal Infirmary of Edinburgh, Lauriston Place, \\ Edinburgh and ${ }^{2}$ Directorate of Accident and Emergency Medicine, Royal Infirmary of Glasgow, Castle \\ Street, Glasgow
}

\section{SUMMARY}

The management of 483 patients presenting with minor head injury to the accident and emergency (A\&E) departments of two Scottish hospitals was studied prospectively. Such patients comprised 5.7 and $3.9 \%$ of the total attendances to each department. Of the 277 patients assessed in the former department, $83(30 \%)$ fulfilled at least one of the currently accepted criteria for recommending admission to hospital and $49(17.7 \%)$ patients were actually admitted. Patients in whom head injury was not the principal reason for admission were excluded from the study. In the same time period the second department dealt with 206 patients with minor head injury, 49 (24\%) of whom had criteria for admission. However, significantly fewer, 10 (4.9\%) patients, were actually admitted. The major relevant factor when comparing the two departments was the existence in the former of an observation ward. These results support the view that easy access to hospital beds is a major determinant of management in patients presenting with minor head injury to the A\&E department and may be more influential than clinical findings.

Key word: guidelines, head injury, management, observation ward

Correspondence:

C. Raine,

Senior House Officer, University Department of Surgery, Royal Infirmary of

Edinburgh, 1 Lauriston Place, Edinburgh $\mathrm{EH} 3$ 9EE, UK

\section{INTRODUCTION}

Patients with head injury comprise approximately $10 \%$ of total attendances at A\&E departments in the UK. ${ }^{1}$ It is estimated that about 1000000 recently head injured patients attend hospital each year in the UK - 1 per 50 of the population. ${ }^{2}$ The great majority of these patients will have sustained minor injury only, however one of the greatest worries for medical staff in A\&E departments is that they might discharge a head injured patient who later develops a complication such as intracranial haematoma or meningitis.

To help identify the group of at-risk attenders, guidelines have been prepared by several groups and are widely used by A\&E doctors working in this country. ${ }^{3,4}$ These include recommendations on those patients who require radiological and other investigations and general aspects of patient management and specialist referral. The primary purpose of these guidelines is to identify those patients at risk of developing complications as a consequence of their injury. Ideally their implementation would also restrict the number of patients with minor head injuries who are admitted to hospital without demonstrable risk ${ }^{5}$ and since their introduction an associated fall in total numbers of head injury admissions has been recorded. ${ }^{6}$

Once the decision has been made by the examining doctor that a head injury attender requires admission, then the patient will most frequently be referred to a primary acute receiving ward. Only a small proportion of these patients, about 3-5\% are referred directly to a neurosurgical unit. ${ }^{2}$ Some A\&E departments have direct access to a 'Short-stay' or 'Observation' ward and when this facility is available it is frequently used to observe the minor head injured patient. The aim of this study was to determine whether access to a short-stay ward significantly affected the threshold for admission of patients with minor head injuries and the implementation of head injury admission guidelines.

\section{METHODS}

A cohort of patients attending two large Scottish teaching hospital A\&E departments was studied, these were Glasgow Royal Infirmary (GRI), and the 
Minor head injuries in A\&E
Royal Infirmary, Edinburgh (RIE). Doctors in both departments are instructed in the use of the head injury guidelines published in 1984 by 'a group of neurosurgeons'. ${ }^{3}$ The A\&E department at GRI has an observation ward allowing doctors working in the department to admit patients with minor head injuries directly to this ward without prior consultation with other specialities. At RIE these patients are referred to the receiving general surgical unit after initial assessment and investigation has been completed by the A\&E doctor.

All patients attending with head injury at both hospitals who were over the age of 13 years, were studied prospectively during the 4-week period 16 November to 13 December 1992. Patients triaged directly to the resuscitation room or who had suffered facial injuries only were excluded from further analysis. The examining doctor was asked to complete a simple questionnaire immediately after seeing the patient (Fig. 1). The questionnaire was carefully worded so as to include all aspects of the guidelines detailed whilst not influencing any decisions the A\&E officer may have made with regard to referral or admission.

At the end of the 4-week study period the records of every A\&E attender were reviewed to assess the number of head injured patients meeting the requirements for entry into the study but for whom no questionnaire had been completed. A figure could then be calculated for the 'pick-up rate' into the study. Results were compared statistically using the chi-squared test.

It should be noted that all patients presenting with minor head injury to both departments and

Fig. 1. Simple questionnaire completed by examining doctor.

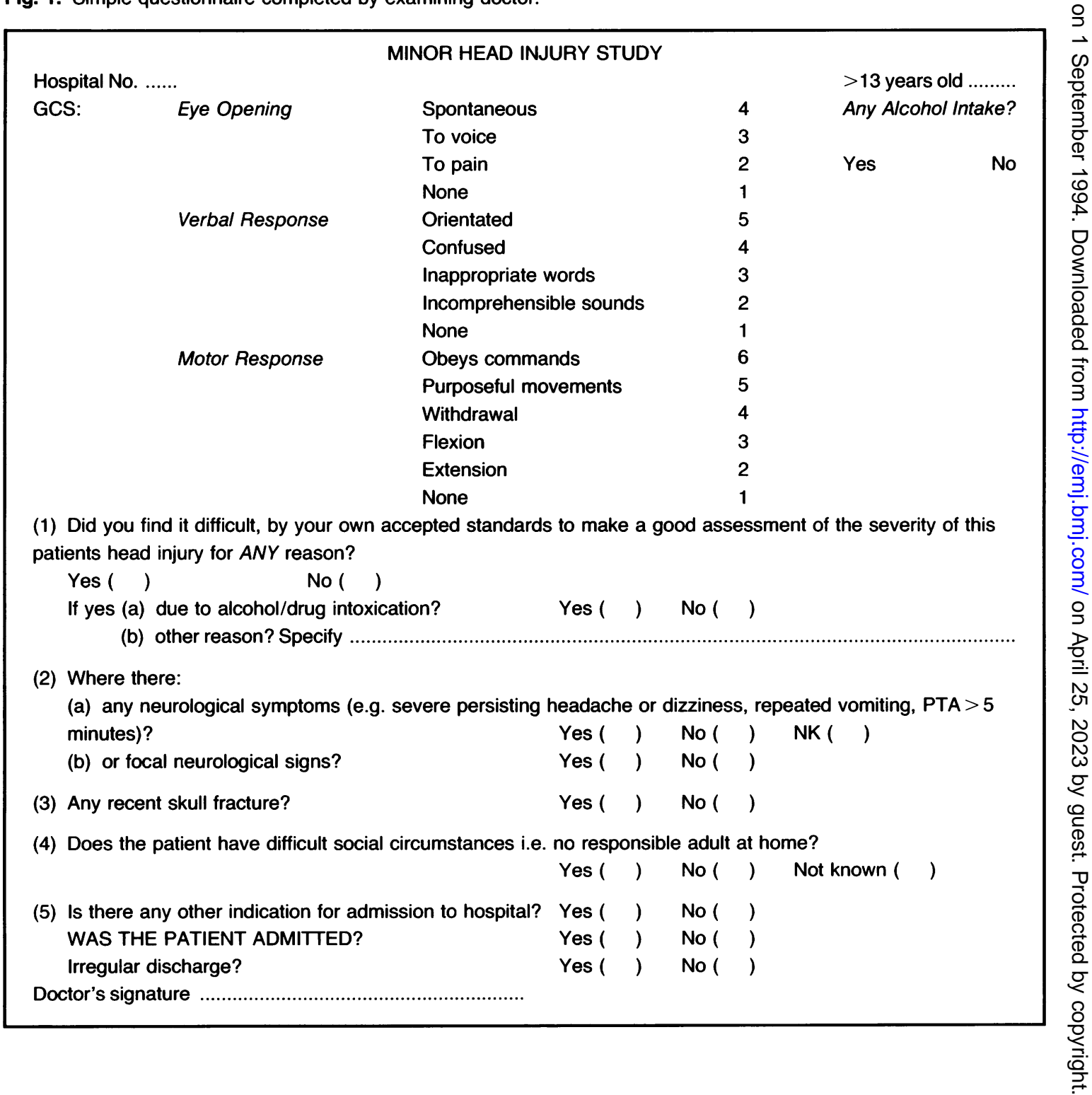


subsequently allowed home were issued with a written head injury warning sheet, together with an accompanying verbal explanation instructing them to return immediately if any of the symptoms detailed developed.

\section{RESULTS}

The two cohorts proved comparable in number and as a percentage of total attendances to each A\&E department. The populations meeting criteria for admission were also similar including the frequency of alcohol ingestion as an associated factor (Table 1). From this data it can be seen that approximately $25-30 \%$ of all attenders with minor head injury meet with at least one admission criterion. There was however a significant difference between the two hospitals in outcome as assessed by the number of patients actually admitted (Table 2). The admission rate in Glasgow of $17.7 \%$ is lower than that previously reported of $23-28 \% .^{1,7}$ This does reflect, however, a relatively high incidence of patient selfdischarge against medical advice. At RIE the proportion is considerably lower (4.9\%).
Table 3 details the distribution of criteria met within each population excluding those patients in whom there were other, extracranial, indications for admission. The most common criterion resulting in admission to hospital in both centres was 'difficulty in assessment'. The figures for RIE relate to those patient who were felt to require admission by the attending A\&E doctor and who were thus referred for a general surgical opinion. Two of these patients were later discharged.

\section{DISCUSSION}

The purpose of the guidlines drawn up in 1984 was twofold. Firstly to avoid discharge from the A\&E department of a head injured patient who later develops potentially life threatening complications, notably intracranial haematoma and meningitis, and secondly to reduce the number of patients with minor head injuries admitted to hospital without demonstrable risk. Clearly they are only guidelines and as such remain open to interpretation. However, in these days of heightening medico legal awareness, to ignore the teachings of experienced specialists

Table 1. A\&E departmental profiles

\begin{tabular}{llcc}
\hline & \multicolumn{3}{c}{ Total number of patients } \\
\cline { 2 - 4 } & GRI (\%) & RIE (\%) & $P$ \\
\hline Total attendances during study period & 5243 & 5750 & \\
Total head injured patients & $299\left(5.7^{*}\right)$ & $226(3.9)$ & $>0.5$ \\
Number entered into study & $277(92)$ & $206(91)$ & $>0.5$ \\
Total attenders meeting criteria & $88\left(31.8^{\dagger}\right)$ & $51(24.8)$ & $>0.05$ \\
$\quad$ recommending admission & & & $>0.1$ \\
Total attenders with criteria and no & $83(30)$ & $49(24)$ & $>0.5$ \\
$\quad$ extracranial indications for admission & $134(48)$ & $97(47)$ & \\
Alcohol on admission & & &
\end{tabular}

Table 2. Outcomes for those patients meeting with at least one criterion recommending admission and with no extracranial indication for admission

\begin{tabular}{llcc}
\hline & \multicolumn{3}{c}{ Total number of patients } \\
\cline { 2 - 4 } & GRI (\%) & RIE (\%) & $P$ \\
\hline Irregular discharge & $19(7)$ & $7(3.4)$ & $>0.05$ \\
Discharged by doctor & $15(5.4)$ & $30+2^{*}(15.5)$ & $<0.001$ \\
Admitted for observation only & $49(17.7)$ & $10(4.9)$ & $<0.001$ \\
\hline
\end{tabular}


Table 3. Distribution of admission criteria in those patients with no extracranial indication for admission

\begin{tabular}{lcccc}
\hline & \multicolumn{4}{c}{ Total number of patients } \\
\cline { 2 - 5 } & & GRI & \multicolumn{2}{c}{ RIE } \\
Criteria & Admitted (\%) & Discharged (\%) & Referred (\%) & Discharged (\%) \\
\hline Confusion & $13(4.7)$ & $1(0.4)$ & $2(1.0)$ & 0 \\
Difficulty in assessment & $33(11.9)$ & $5(1.8)$ & $8(3.9)$ & $12(5.8)$ \\
Neurological symptoms & $19(6.9)$ & $7(2.5)$ & $5(2.4)$ & $25(12.1)$ \\
Neurological signs & 0 & $1(0.4)$ & $1(0.5)$ & $2(1.0)$ \\
Recent skull fracture & $6(2.2)$ & 0 & $2(1.0)$ & 0 \\
Difficult social circumstance & $9(3.2)$ & $4(1.4)$ & $5(2.4)$ & $10(4.9)$ \\
\hline
\end{tabular}

Percentages are of study group

must surely be inadvisable. Table 2 shows that at RIE three times as many patients who met with accepted guidelines for admission were discharged in comparison with GRI, the major relevant factor when comparing the two departments being the existence in Glasgow of an observation ward.

One explanation for the difference shown lies in the fact that A\&E doctors in RIE must refer any prospective admissions with minor head injury to the general surgeon on call. In the majority of hospitals the on-call surgeons are busy and unwilling to fill their surgical beds with what frequently turn out to be non-surgical patients. This undoubtedly influences the willingness of the A\&E doctor to refer such patients to his or her surgical colleague, especially late at night when such patients are frequently encountered. In addition the general surgeon may discharge cases once they have been referred (two out of the 12 referrals at RIE). It is important, therefore, that the on call general surgeon is also fully acquainted with the guidelines for admission of these patients. At GRI the same doctor would admit such a patient directly to the observation ward. Both $A \& E$ departments run induction programmes twice a year for the benefit of their new doctors which include explanation and discussion of the recommended guidelines for initial management of the head injured patient.

The incidence of alcohol consumption prior to attendance at the A\&E department was similar in both centres with approximately half of all attenders admitting to having taken at least some alcohol. It has been shown previously that injury while under the influence of alcohol is not only more severe, but the important signs of more serious injury are disguised. ${ }^{8}$ This group of patients in particular are reluctantly admitted to a acute surgical bed as frequently occurring aggressive and uncooperative behaviour can make their admission disruptive to the continuing care of the other patients.

The numbers studied are too small to comment on outcome but it has been shown that in patients with head injuries and no skull fracture, but who are disorientated, (including the drunken head injury) the incidence of intracranial haematoma is 1 in 120 , in those with no skull fracture and no altered consciousness the incidence falls to only 1 in $6000 .^{9}$

The results of this study show that access to a short stay ward has considerable bearing on whether or not a minor head injured patient is admitted to hospital and illustrates the clear differences that still exist in the management of this common problem. This is despite the fact that identical guidelines are used by the two centres studied and adds considerable weight to the view that ease of access to hospital beds is a major determinant of management in patients presenting with minor head injury to the A\&E department and may be more influential than clinical findings. Further refinements to these guidelines may be required to increase the concordance of their interpretation both between individual doctors and between the centres that advocate their use. This would render them a more practical tool for use in A\&E departments and bring them closer to achieving the aims for which they were designed.

\section{REFERENCES}

1. Strang I., MacMillan R. \& Jennett B. (1978) Head injuries in accident and emergency departments at Scottish hospitals. Injury 10, 154-159.

2. Jennett B. \& McMillan R. (1981) Epidemiology of head injury. British Medical Journal 282, 101-104. 


\section{S.R. Brown et al.}

3. A Group of Neurosurgeons (1984) Guidelines for initial management after head injury in adults. British Medical Journal 288, 983-985.

4. Weston P.A. (1981) Admission policy for patients following head injury. British Journal of Surgery 68, 663-664.

5. Mendelow A.D., Campbell D.A., Jeffrey R.R., Miller J.D., Hessett C., Bryden J. \& Jennett B. (1982) Admission after mild head injury; benefits and costs. British Medical Journal 285, 1530-1532.

6. Miller J.D., Jones P.A., Dearden N.M. \& Tocher J.L. (1992) Progress in the management of head injury.
British Journal of Surgery 79, 60-64.

7. Swann I.J., MacMillan R. \& Strang I. (1981) Head injuries at an inner city accident and emergency department. Injury 12, 274-278.

8. Robertson C. \& Redmond A.D. (1991) The Management of Major Trauma, pp. 51-52. Oxford University Press, Oxford.

9. Mendelow A.D., Teasdale G., Jennett B., Bryden J., Hessett C. \& Murray G. (1983) Risks of intracranial haematoma in head injured adults. British Medical Journal 287, 1173-1176. 